\title{
Rheological behaviour of vitreous humour
}

\author{
Andreia F. Silva ${ }^{1} \cdot$ Manuel A. Alves ${ }^{2} \cdot$ Mónica S. N. Oliveira ${ }^{1}$
}

Received: 18 August 2016/Revised: 6 December 2016 / Accepted: 11 January 2017 / Published online: 7 February 2017

(C) The Author(s) 2017. This article is published with open access at Springerlink.com

\begin{abstract}
The vitreous humour (VH) is a complex biofluid that occupies a large portion of the eyeball between the lens and the retina, and exhibits non-Newtonian rheological properties that are key for its function in the eye. It is often possible to distinguish two different phases in $\mathrm{VH}$, known as liquid and gel phases (Sebag J Eye 1: 254-262, 1987). In this work, we present a detailed rheological characterisation of the two phases of the $\mathrm{VH}$ under shear and extensional flow conditions. Healthy New Zealand rabbit eyes were used to measure the surface tension and the shear and extensional rheological properties of $\mathrm{VH}$ in different phase conformations and at different times after dissection. The results show that $\mathrm{VH}$ liquid phase exhibits a surface tension of $47.8 \mathrm{mN} / \mathrm{m}$, a shear thinning behaviour reaching a viscosity plateau around $10^{-3} \mathrm{~Pa} \mathrm{~s}$ for shear rates above $\sim 1000 \mathrm{~s}^{-1}$, and an average relaxation time of $9.7 \mathrm{~ms}$ in extensional flow. Interestingly, both $\mathrm{VH}$ phases present higher storage modulus than loss modulus, and the measurements performed with VH gel phase $4 \pm 1 \mathrm{~h}$ after dissection exhibit the highest moduli values. The compliance measurements for the gel phase show a viscoelastic gel behaviour and that compliance values decrease substantially with
\end{abstract}

Mónica S. N. Oliveira

monica.oliveira@strath.ac.uk

Andreia F. Silva

andreia.silva@strath.ac.uk

Manuel A. Alves

mmalves@fe.up.pt

1 James Weir Fluids Laboratory, Department of Mechanical and Aerospace Engineering, University of Strathclyde, Glasgow G1 1XJ, UK

2 Departamento de Engenharia Química, CEFT, Faculdade de Engenharia, Universidade do Porto, 4200-465 Porto, Portugal time after dissection. Our results show that the two $\mathrm{VH}$ phases exhibit viscoelastic behaviour, but with distinct rheological characteristics, consistent with a gel phase mostly composed of collagen entangled by hyaluronan and a second phase mainly composed of hyaluronan in aqueous solution.

Keywords Vitreous humour · Biorheology · Biofluid · Eye

\section{Introduction}

The vitreous humour $(\mathrm{VH})$ is a transparent gelatinous avascular structure that fills the space between the lens and the retina in the eye (Chirila et al. 1998; Nickerson et al. 2005; Nickerson et al. 2008; Sharif-Kashani et al. 2011; Siggers and Ethier 2012). There have been various attempts to describe the vitreous structure and its composition (Fromm 1921; Sebag 2002; Sebag and Balazs 1985), and it is now accepted that $\mathrm{VH}$ is composed of $\sim 99 \%$ water, $\sim 0.9 \%$ of salts, and $\sim 0.1 \%$ of a network of fine collagen fibrils and hyaluronan that form a scaffolding (Bishop 2000; Sharif-Kashani et al. 2011). The collagen concentration in VH is around 40 $120 \mu \mathrm{g} / \mathrm{cm}^{3}$, and collagen type II is the most abundant type of collagen in the eye (Black and Hastings 1998; de Smet et al. 2013). Hyaluronic acid (HA) or hyaluronan is the major glycosaminoglycan in the VH structure (Bishop 1996; de Smet et al. 2013) with a concentration of $100-400 \mu \mathrm{g} / \mathrm{cm}^{3}$ (Black and Hastings 1998). The gelatinous nature of the vitreous body is a result of the long collagen fibrils suspended in patterns of HA molecules (cf. Fig. 1), which surround and stabilise the water molecules and proteoglycans.

The fibre networks increase in density away from the centre, especially so at the edge of the vitreous to form the bounding anterior and posterior hyaloid membranes (Lee 1992). In human eyes, VH typically occupies a volume of 


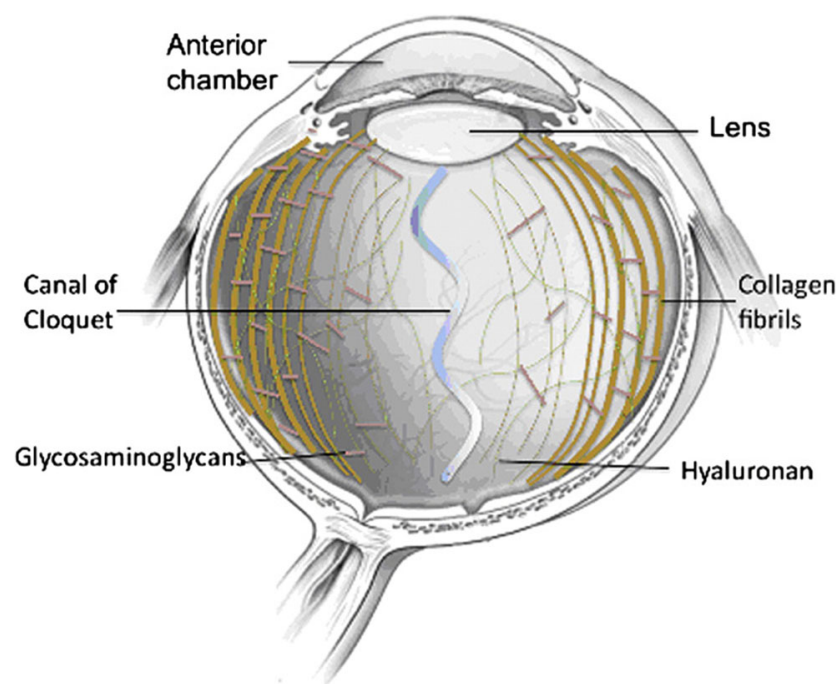

Fig. 1 Vitreous humour structure (reprinted from Laude et al. 2010 with permission from Elsevier)

$4 \mathrm{ml}$, has a neutral $\mathrm{pH}$ (between 7.0 and 7.4), a density in the range $1.0053-1.0089 \mathrm{~g} / \mathrm{cm}^{3}$, and a refractive index between 1.3345 and 1.3348 (Baino 2011; Black and Hastings 1998; Lee 1992). The volume and composition of VH varies between different species. VH in rabbit eyes occupies around $1-2 \mathrm{ml}$, has a collagen content of 75-900 $\mu \mathrm{g} / \mathrm{cm}^{3}$, and HA content of 20 $60 \mu \mathrm{g} / \mathrm{cm}^{3}$ (Kleinberg et al. 2011). Previous studies have shown that the $\mathrm{VH}$ from rabbit eyes is a good pharmacokinetic model of human eyes (del Amo and Urtti 2015; Kleinberg et al. 2011).

The presence of both HA and collagen together in the vitreous natural molecular architecture is responsible for the viscoelastic properties of the VH (Kleinberg et al. 2011). As a viscoelastic gel, the VH exhibits both solid- and liquid-like behaviour (Swindle and Ravi 2007). Furthermore, the distribution of collagen fibre network and HA network is not homogeneous, and consequently, the rheological properties of vitreous humour vary along the vitreous cavity (Black and Hastings 1998; Kleinberg et al. 2011; Lee 1992; Swindle and Ravi 2007). Lee (1992) showed that the viscosity is higher in the posterior region and decreases toward the anterior segment. The author argues that the $\mathrm{VH}$ is more viscous at the posterior segment in order to protect the retina and less viscous at the anterior segment in order to allow rapid accommodation.

In terms of the rheological characterisation of the $\mathrm{VH}$, most studies focus on the measurement of the $\mathrm{VH}$ storage modulus $\left(G^{\prime}\right)$ and loss modulus $\left(G^{\prime \prime}\right)$ to characterise the viscoelastic behaviour (Bettelheim and Wang 1976; Filas et al. 2014; Lee 1992; Nickerson et al. 2008; Sharif-Kashani et al. 2011; Swindle et al. 2008), where $G^{\prime}$ represents the elastic or recoverable component, and $G^{\prime \prime}$ represents the viscous component related to the dissipated energy. Those studies reveal that $\mathrm{VH}$ has a higher storage modulus than loss modulus, indicating its viscoelastic solid-like behaviour. Nickerson et al. (2008) developed a novel cleat geometry to overcome wall slip in shear rheometry and reported $G^{\prime}$ and $G^{\prime \prime}$ values measured right after dissection to be 32 and $17 \mathrm{~Pa}$ for bovine $\mathrm{VH}$, and 10 and 3.9 Pa for porcine VH. They reported a storage modulus higher than all other sources, which was found to decrease with time after collection (i.e., when outside the eye) approaching steady-state values of $G^{\prime}=7.0 \mathrm{~Pa}$ and $G^{\prime \prime}=2.2 \mathrm{~Pa}$ for bovine, and $G^{\prime}=2.8 \mathrm{~Pa}$ and $G^{\prime \prime}=0.7 \mathrm{~Pa}$ for porcine $\mathrm{VH}$, suggesting that the moduli are even higher in vivo. Sharif-Kashani et al. (2011) measured the dynamic deformation, the shear stress-strain flow, and the creep compliance of porcine $\mathrm{VH}$ using a stress-controlled shear rheometer. For small amplitude oscillatory shear (SAOS) flow experiments, they concluded that only the results with frequencies in the range $\omega=0.1-10 \mathrm{rad} / \mathrm{s}$ were reliable and the average values obtained for the storage and loss moduli were $G^{\prime}=1.08 \pm 0.22 \mathrm{~Pa}$ and $G^{\prime \prime}=0.25 \pm 0.07 \mathrm{~Pa}$, respectively. Regarding creep tests for $\mathrm{VH}$, three distinct regions were described in the literature (Sharif-Kashani et al. 2011): an elastic region (that lasts approximately $1 \mathrm{~s}$ ), a retardation region ( $80 \mathrm{~s}$ ), and a viscous region. Based on this behaviour, the authors proposed a viscoelastic model consisting of two VoigtKelvin elements in series. Additionally, Filas et al. (2014) measured both moduli for bovine and porcine eyes, in its natural conformation and also after digesting the samples with hyaluronidase and collagenase. The authors observed that bovine VH samples show higher moduli values than porcine $\mathrm{VH}$. When the sample was digested with collagenase (loss of collagen), the sample becomes more liquid, and when digested with hyaluronidase (loss of HA), the sample becomes more elastic. Despite the progress in the experimental characterisation of VH properties, its rheology is still not fully understood (Siggers and Ethier 2012).

Rearrangements of the macromolecular structure of $\mathrm{VH}$ occur with ageing, which result in the liquefaction of the vitreous (Balazs and Denlinger 1982; Los et al. 2003): the $\mathrm{VH}$ undergoes a transformation from a formed gel to a phase-separated fluid. Three different categories of rearrangements are reported: rheological, biochemical, and structural (Sebag 1987; Walton et al. 2002). For an age as early as 4 years old, the vitreous may start to liquefy and by the time the eye reaches adult size (1418 years), $20 \%$ of the vitreous is liquid (Balazs and Denlinger 1982; Bishop 2000; Le Goff and Bishop 2008). After the age of 40 years old, a continuous increase in liquid vitreous associated with a decrease in the gel volume is observed (Bishop 2000). The mechanism involved in the liquefaction of $\mathrm{VH}$ is still not clearly understood, but several studies show that the conformational changes of the collagen play a key role in the process. Young vitreous shows a homogeneous distribution, but with age, a breakdown of collagen fibrils into smaller fragments seems to be crucial to the pathogenesis of age- 
related liquefaction of VH (Sebag 1987; Sebag 1993; Walton et al. 2002). The gel portion of the vitreous collapses, a process called syneresis, leading to an increase of collagen and of the optical dense areas. Simultaneously, there is a progressive increase in the volume of liquefied spaces (synchysis) (Los et al. 2003; Walton et al. 2002). Liquefaction is noticeable mainly in the central vitreous where collagen concentration is lower (Le Goff and Bishop 2008). Increased liquefaction leads to changes in shear viscosity and elasticity and consequently causes variations in the fluid dynamics of the vitreous and its behaviour during eye movements (Baino 2010).

The liquefaction process of the vitreous can lead to a decrease or even loss of the VH viscoelasticity and consequently to the appearance of diseases related with $\mathrm{VH}$, such as retinal detachment and retinal tears (Le Goff and Bishop 2008; Mitry et al. 2010). However, previous studies showed that some diseases can also lead to modifications in the VH structure: diabetic patients show glucose levels in $\mathrm{VH}$ higher than healthy patients, which leads to collagen glycation in early stages that promotes the cross-linking of $\mathrm{VH}$ collagen network and consequently liquefaction of VH (Le Goff and Bishop 2008; Lundquist and Osterlin 1994; Sebag 1993; Sebag and Balazs 1985; Sebag et al. 1994; Stitt et al. 1998).

It has been reported that it is possible to distinguish the two different $\mathrm{VH}$ phases even for young eyes and that some diseases of the $\mathrm{VH}$ are the result of changes in the collagen component within the cortical gel, and age-related vitreous degenerations are usually a manifestation of dissociation of collagen and hyaluronan (Sebag 1987; Sebag and Balazs 1985; Stitt 2005).

The main goal of the present study is to quantify experimentally the rheological properties of VH gel and VH liquid phases separately. Shear rheology experiments were performed for both phases, and the extensional rheological properties of $\mathrm{VH}$ liquid phase were also measured. The remainder of the paper is organised as follows: the next section presents an overview of the methodology followed; the results are then presented and discussed; finally, the main conclusions are summarised in the last section.

\section{Methodology}

\section{Sample dissection}

All samples were collected from healthy New Zealand white rabbit specimen, aged $18 \pm 3$ weeks and weighing between 2.8 and $3.0 \mathrm{~kg}$. All rabbit eye samples were collected on the day of the experiments and the tests were performed within $5 \mathrm{~h}$ post-mortem. The rabbits were euthanised and the eyes were used in parallel with other research projects to minimise animal usage. During the dissection, it is possible to observe two distinct phases: a liquid-like and a gel phase. We should also note that the samples start to change their conformation as a result of being highly fragile in nature (Sebag and Balazs 1985). Nickerson et al. (2008) suggest that the collagen and some amount of hyaluronan remain in the gel phase while the exudate fluid contains mostly hyaluronan, as illustrated in Fig. 2. Three different conformations of VH were considered in this work: the gel phase right after dissection, the gel phase hours after dissection, and the liquid phase hours after dissection. The first experiments with the VH gel phase samples started less than 5 min after the dissection of the sample, and the fluid was moved from a closed environment, the vitreous cavity, to another closed environment, between the rheometer plates with a solvent trap. The delayed measurements of both the gel and liquid phases of VH were performed within a maximum of 4 $\pm 1 \mathrm{~h}$ after the dissection of the eyes.

\section{Surface tension}

The surface tension measurements were made with a drop shape analyser (model DSA25, Krüss) using the pendant drop method. Measurements were performed only for the liquid phase, in different days and with different samples, to assess the reproducibility of the results. The measurements were performed at a temperature of $T=21 \pm 2{ }^{\circ} \mathrm{C}$. The shape of the pendant drop was fitted to the Young-

Fig. 2 a Schematics of vitreous humour enclosure in the eye (native state) and after separation in two different phases: $\mathbf{b}$ gel phase mostly composed by collagen fibrils and a small amount of hyaluronan and $\mathbf{c}$ liquid phase mostly composed by hyaluronan, adapted from Nickerson et al. 2008

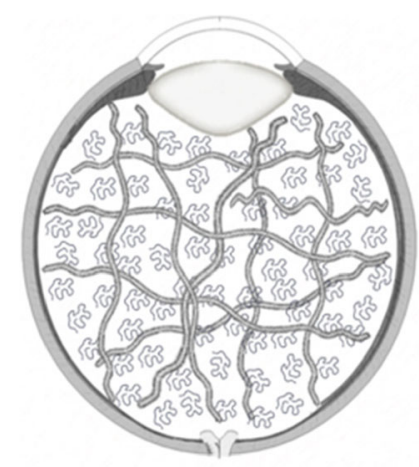

(a)

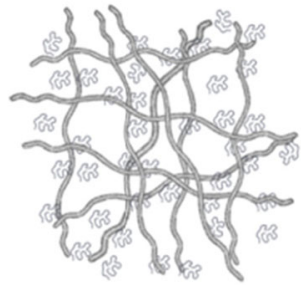

(b)

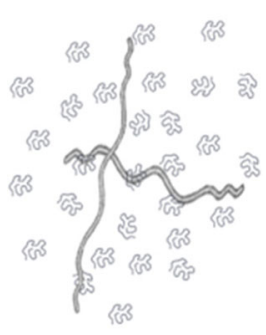

(c) 
Laplace equation with the surface tension, $\sigma$, as the fitting parameter, described by

$\Delta p=\sigma\left(\frac{1}{r_{1}}+\frac{1}{r_{2}}\right)$

where $\Delta p$ is the pressure difference across the interface, and $r_{1}$ and $r_{2}$ are the principal radii of curvature of the surface.

\section{Rotational rheology}

Shear measurements were performed using a DHR-2 rheometer (TA Instruments) and two different geometries were used: a cone-plate with $60 \mathrm{~mm}$ diameter and $1^{\circ}$ cone angle to measure the liquid phase and a $40 \mathrm{~mm}$ diameter plate-plate system to measure the gel phase. The plate geometry was covered with 500 grit silicon carbide sandpaper to minimise wall slip and provide an effective no-slip boundary condition (Nickerson et al. 2008; Sharif-Kashani et al. 2011).

Small amplitude oscillatory shear (SAOS) measurements were performed at $T=20^{\circ} \mathrm{C}$ and at $T=37{ }^{\circ} \mathrm{C}$, closer to the normal body temperature, for a strain $\gamma=1 \%$ and frequency $\omega=10 \mathrm{rad} / \mathrm{s}$ or $\omega=1 \mathrm{rad} / \mathrm{s}$. No meaningful differences were found between the experiments performed at both temperatures. The conditions for these experiments were based on the dynamic moduli as a function of strain performed with $\gamma=0.1-50 \%$ and a frequency $\omega=10 \mathrm{rad} / \mathrm{s}$. The flow curve measurements for the liquid phase were performed with a solvent trap maintaining a water-saturated atmosphere at $T=20$ and $37{ }^{\circ} \mathrm{C}$. Creep compliance experiments were also performed with a solvent trap maintaining a water-saturated atmosphere at $T=37^{\circ} \mathrm{C}$ for a duration of $2000 \mathrm{~s}$, at constant applied shear stresses of $\tau=1.0$ and 2.0 Pa.

\section{Extensional rheology}

Extensional tests were also performed with the liquid phase in a Capillary Breakup Extensional Rheometer (HAAKETM CaBER $^{\mathrm{TM}} 1$ ), which imposes a uniaxial extensional deformation to the fluid samples. A step strain with $50 \mathrm{~ms}$ duration was imposed in all experiments. All the measurements were performed at $T=37{ }^{\circ} \mathrm{C}$. Experiments considering imposed Hencky strains $\left(\varepsilon=\ln \left(h_{f} / h_{i}\right)\right)$ of 1.23 and 1.64 were performed, where $h_{i}$ and $h_{f}$ are the initial and the final gaps between the plates.

\section{Results and discussion}

\section{Surface tension}

The average value measured of surface tension for the liquid phase was $\sigma=47.8 \pm 3.8 \mathrm{mN} / \mathrm{m}$ (see Table 1). There was no significant difference observed in the measurements right after dissection or a few hours after dissection (average values of 47.1 and $48.6 \mathrm{mN} / \mathrm{m}$, respectively). In Fig. 3, we show an example of a pendant drop of the VH liquid phase visualised during the surface tension experiments. To the best of our knowledge, only Ross et al. (2010) presented measurements with the VH collected from rabbits, reporting an average surface tension of $60.6 \pm 2.6 \mathrm{mN} / \mathrm{m}$. Our measurements with the liquid phase exhibit lower values of surface tension, but closer to the results presented by Li et al. (2006) for HA solutions, which is consistent with the main component of the liquid phase being hyaluronan (Nickerson et al. 2008). $\mathrm{Li}$ et al. (2006) performed a series of surface tension measurements with hyaluronic acid solutions at different concentrations and in solutions with gelatine and/or $N, N$ dimethylformamide, showing that for aqueous solutions of hyaluronic acid (1.3 and 1.5 HA $w / v \%)$, the surface tension measured varied between 52 and $53 \mathrm{mN} / \mathrm{m}$.

\section{Steady shear flow experiments}

Figure 4 shows the steady shear experiments performed with the VH liquid phase, measured at $T=37^{\circ} \mathrm{C}$.

In the stress-controlled experiments (see Fig. 4a), for shear stresses below $0.2 \mathrm{~Pa}$, the measured viscosity of the $\mathrm{VH}$ liquid phase is very high (above $200 \mathrm{~Pa} \mathrm{~s}$ ) and the corresponding shear rate is very small. For a shear stress around $0.2 \mathrm{~Pa}$, a sudden decrease in the shear viscosity of more than four orders of magnitude is observed, from more than $200 \mathrm{~Pa}$ s to a value around $0.003 \mathrm{~Pa}$, while the shear rate increases abruptly. For the shear rate-controlled experiments (see Fig. 4b), the viscosity exhibits shear thinning with a power-law behaviour, $\tau \propto \gamma^{-1}$, with a value around $20 \mathrm{~Pa} \mathrm{~s}$ for a shear rate of $0.01 \mathrm{~s}^{-1}$ reaching a value around $10^{-3} \mathrm{~Pa}$ for shear rates above $\sim 1000 \mathrm{~s}^{-1}$.

Although we are not aware of any comparable studies in the literature, it is instructive to compare our results with some
Table 1 Surface tension obtained for VH liquid phase at $T=21$ $\pm 2{ }^{\circ} \mathrm{C}$, using the Young-Laplace equation with a pendant drop

\begin{tabular}{lll}
\hline & $\begin{array}{l}\text { Average surface tension } \\
(\mathrm{mN} / \mathrm{m})\end{array}$ & $\begin{array}{l}\text { Standard deviation } \\
(\mathrm{mN} / \mathrm{m})\end{array}$ \\
\hline Measurement immediately after dissection & 47.1 & 2.8 \\
Delayed measurement within 4 \pm 1 h after dissection & 48.6 & 4.4 \\
All measurements & 47.8 & 3.8 \\
\hline
\end{tabular}




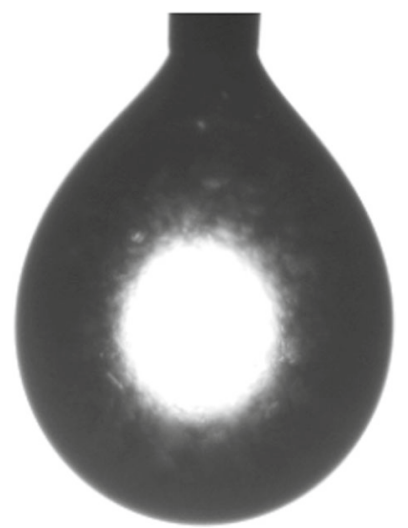

Fig. 3 Example of an image of a pendant drop of vitreous humour liquid phase captured for the determination of the surface tension

studies with HA solutions (Ambrosio et al. 1999; Maleki et al. 2007), which is believed to be one of the main components of the liquid phase, and with some biological fluids in which the main constituent is HA (Bingol et al. 2010; Fam et al. 2009; Haward 2014; Haward et al. 2013). HA solutions are shear thinning and both the values and the characteristics of the flow curve are dependent of the concentration of HA, the molecular weight, the molecular conformation of HA, and, consequently, the interactions between them (Ambrosio et al. 1999; Bingol et al. 2010; Fam et al. 2009; Haward 2014; Haward et al. 2013; Maleki et al. 2007). Fam et al. (2009) measured the rheological properties of different concentrations of hyaluronic acid/bovine calf serum (BCS) solutions that can be used as analogues of synovial or periprosthetic fluids. The flow curve measured in this work is in the same range of values as the $1 \mathrm{mg} / \mathrm{ml} \mathrm{HA}$ solution (HA with a molecular weight of $2.48 \mathrm{MDa}$ ). Bingol et al. (2010) characterised the rheological properties of sodium hyaluronate samples with different concentrations and of synovial fluid taken postmortem from different patients. Similarly to our findings, those authors also observed a shear thinning behaviour of the biofluid and variability from donor to donor.

\section{SAOS experiments}

Small amplitude oscillatory shear measurements were performed using different samples with the gel and liquid phases and repeated at different elapsed times after dissection. A strain sweep was carried out at constant frequency, $\omega=10 \mathrm{rad} / \mathrm{s}$ (for the liquid phase and the gel phase $4 \pm 1 \mathrm{~h}$ after dissection). The effect of the imposed oscillatory strain on the viscous and elastic moduli is illustrated in Fig. 5, and it is possible to observe that both the liquid and the gel phases are in the linear regime ( $G^{\prime}$ and $G^{\prime \prime}$ constant) at least up to $\gamma \cong 1 \%$.

Figure 6 shows the frequency sweep response for the three different types of sample under a strain amplitude of $\gamma=1 \%$, selected to be in the linear regime based on the strain sweep experiments (cf. Fig. 5): the gel phase immediately after dissection, the gel phase $4 \pm 1 \mathrm{~h}$ after dissection, and the liquid phase. Figure 6a also shows $G^{\prime}$ measurements performed with water (which ideally should be zero) for comparison. It is clear that the $G^{\prime}$ values of the VH samples are at least three orders of magnitude higher than the baseline of the equipment. Additionally, only data exhibiting a raw phase below $90^{\circ}$ is presented in Fig. 6 (Ewoldt et al. 2015). The VH gel phase right after dissection is the sample with the properties most similar to the VH in its natural environment (Nickerson et al. 2008). Even if the shape and conformation of the fluid during the experiment is not exactly the same as in vitreous cavity, it is the closest to the conformation of VH in the vitreous cavity that is possible to study ex vivo. In this conformation, the collagen networks actively interact with the hyaluronan molecules, which are responsible for the VH properties: it is believed that the hyaluronan molecules are bound to the collagen fibrils, stabilising the collagen conformation and reinforcing the vitreous structure (Bos et al. 2001; Nickerson et al. 2008). Nickerson et al. (2008) hypothesised that the hyaluronan increases the moduli by placing the collagen network under internal tension. The average and standard deviation of $G^{\prime}$ and $G^{\prime \prime}$ for all samples analysed are shown in Fig. 6.
Fig. 4 Shear measurements with the $\mathrm{VH}$ liquid phase, measured at $T=37^{\circ} \mathrm{C}$. a Shear viscosity and shear rate as function of shear stress for a stress-controlled experiment. b Shear viscosity as function of shear rate for shear rate-controlled experiment and comparison with the shear viscosity predicted using the CoxMerz rule using the SAOS measurements

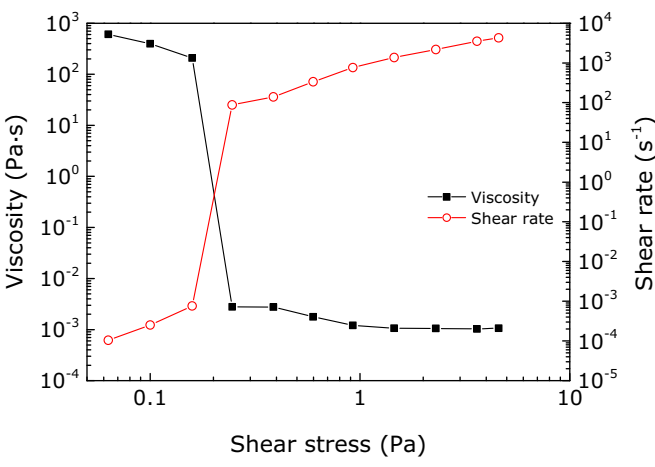

(a)

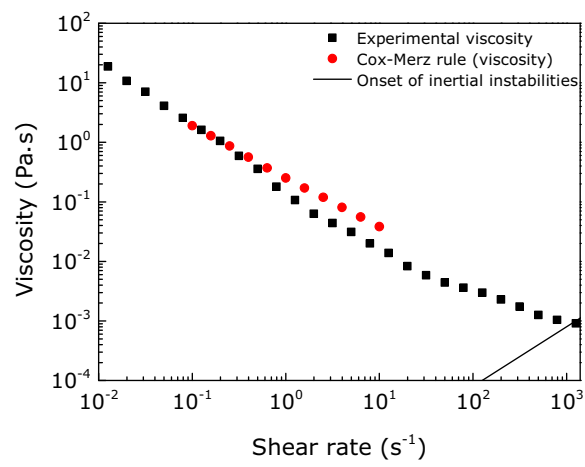

(b) 


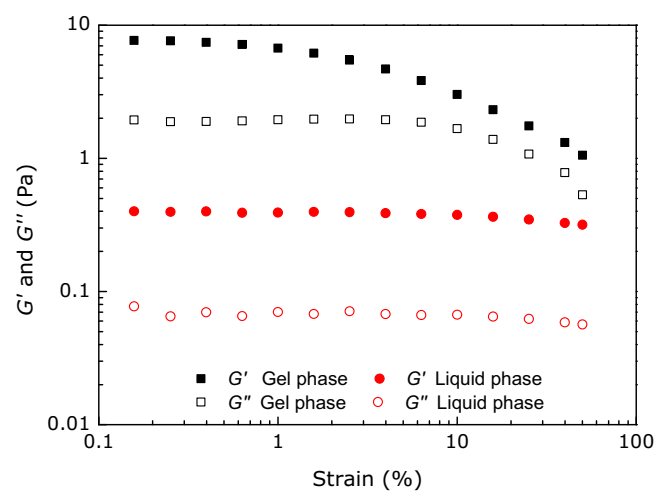

Fig. 5 SAOS measurements at different strains conducted with the liquid and the gel phases at $T=37^{\circ} \mathrm{C}$ and a constant frequency, $\omega=10 \mathrm{rad} / \mathrm{s}$

As expected for biofluids, there is donor to donor variability, and, as a result, the measurements repeated with samples from different rabbit eyes and in different days, even under similar experimental conditions, present a significant variability. The oscillatory measurements show that $G^{\prime}$ and $G^{\prime \prime}$ are higher in the gel phase measured $4 \pm 1 \mathrm{~h}$ after dissection than right after dissection. Measurements with the gel phase (both right after dissection and $4 \pm 1 \mathrm{~h}$ after the dissection) show that for all the frequencies, $G^{\prime}$ is in average higher than $G^{\prime \prime}$, indicating that a solid-like behaviour dominates (Barnes 2000). For the liquid phase, both $G^{\prime}$ and $G^{\prime \prime}$ are lower than the gel phase, and the elapsed time after dissection does not seem to significantly influence the linear viscoelasticity of the fluid for the time frame investigated. Nevertheless, $G^{\prime}$ is also higher than $G^{\prime \prime}$ for the range of frequencies tested and the fluid can be considered as a weak gel (Picout and Ross-Murphy 2003). We, however, still refer to it as liquid phase for consistency with previous works (Balazs and Denlinger 1982; Bishop 2000; Los et al. 2003; Sebag 1987). Similarly, Nickerson et al. (2008) showed that for variable frequency experiments, the broad plateau modulus region expected for gels occurs below $\omega=5 \mathrm{rad} / \mathrm{s}$. As such, we will base our analysis on values obtained for $\omega=1 \mathrm{rad} / \mathrm{s}$ (see Table 2). Using the Cox-Merz rule (Manero et al. 2002), we can estimate the shear viscosity in steady shear flow from the SAOS measurements. The results obtained are included in Fig. 4b, showing the applicability of this empirical rule for $\mathrm{VH}$ liquid phase at lower shear rates (between $\dot{\gamma}=0.1$ and $10 \mathrm{~s}^{-1}$ ).

Fam et al. (2009) performed SAOS experiments with hyaluronic acid/bovine calf serum solutions. For solutions with concentrations of HA between 3 and $4 \mathrm{mg} / \mathrm{ml}$, the storage modulus is in the same range of values of the $\mathrm{VH}$ liquid phase, but the loss modulus is not $\left(G^{\prime}\right.$ between 0.1 and $0.8 \mathrm{~Pa}$ and $G^{\prime \prime}$ around $1 \mathrm{~Pa}$, for $\omega=1 \mathrm{rad} / \mathrm{s}$ ), indicating that the elastic behaviour is similar, but the VH liquid phase shows a less viscous character than the HA solutions.

For the $\mathrm{VH}$ gel phase measured right after dissection and for a constant frequency of $\omega=1 \mathrm{rad} / \mathrm{s}, G^{\prime}$ shows an average value of $1.86 \mathrm{~Pa}$ (standard deviation of $1.14 \mathrm{~Pa}$ ) and $G^{\prime \prime}$ presents an average value of $0.61 \mathrm{~Pa}$ (standard deviation of $0.39 \mathrm{~Pa}$ ) (see Table 2). The moduli results are in the same range of those presented by Sharif-Kashani et al. (2011), Nickerson et al. (2008), and Filas et al. (2014): in the measurements performed by Sharif-Kashani et al. (2011) right after dissection, the storage modulus varies between 1 and $2 \mathrm{~Pa}$ and the loss modulus between 0.2 and $0.3 \mathrm{~Pa}$; Nickerson et al. (2008) obtained an elastic modulus $G^{\prime} \simeq 2$ Pa and a viscous modulus $G^{\prime \prime} \simeq 0.1 \mathrm{~Pa}$ for a frequency of $\omega=1 \mathrm{rad} / \mathrm{s}$, also immediately after dissection; finally, Filas et al. (2014) measured $G^{\prime} \simeq 3 \mathrm{~Pa}$ and $G^{\prime \prime} \simeq 1 \mathrm{~Pa}$ for porcine eyes. These small discrepancies may be explained by the difference in the amount of HA and collagen content between rabbit and porcine eyes: collagen content in the eyes of rabbits varies between 75 and $900 \mu \mathrm{g} / \mathrm{ml}$ while in pig's eyes is $\sim 20 \mu \mathrm{g} / \mathrm{ml}$, while HA content varies in the range $20-60 \mu \mathrm{g} / \mathrm{ml}$ in rabbit eyes and $70-80 \mu \mathrm{g} / \mathrm{ml}$ in porcine eyes (Kleinberg et al. 2011). As shown by Filas et al. (2014), the differences in HA and collagen content can significantly change the moduli of the samples. Our SAOS measurements with VH gel $4 \pm 1 \mathrm{~h}$ after dissection (Table 2) compare well with the measurements of Shayegan and Forde (2013) with collagen solutions: $G$ ' varies between 3 and $20 \mathrm{~Pa}$, while $G^{\prime \prime}$ varies between 0.01 and $1 \mathrm{~Pa}$ for a frequency of $\omega=1 \mathrm{rad} / \mathrm{s}$.
Fig. 6 a Storage $\left(G^{\prime}\right)$ and $\mathbf{b}$ loss $\left(G^{\prime \prime}\right)$ moduli of the gel and liquid phases of $\mathrm{VH}$ as function of frequency for constant strain amplitude, $\gamma=1 \%$, measured at $T=37^{\circ} \mathrm{C}$

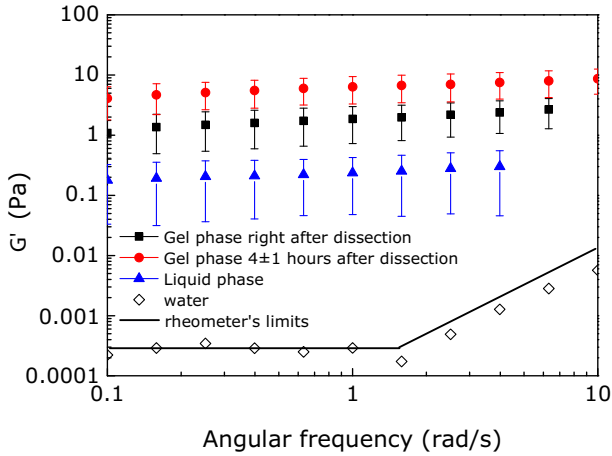

(a)

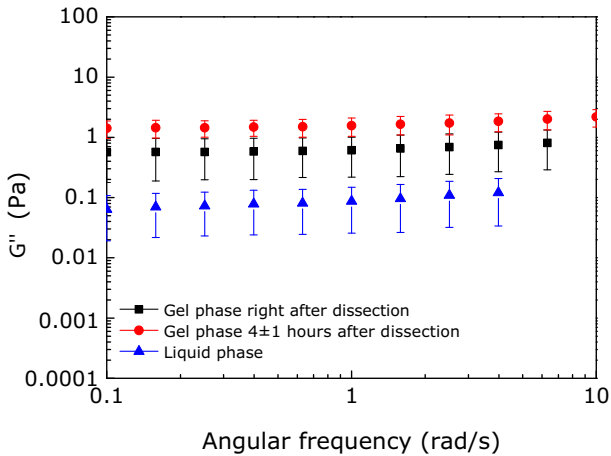

(b) 
Table 2 Average values obtained for storage and loss moduli for the VH liquid phase and VH gel phase right after dissection and 4 $\pm 1 \mathrm{~h}$ after dissection. The values were obtained for a strain amplitude $\gamma=1 \%$ and a constant frequency, $\omega=1 \mathrm{rad} / \mathrm{s}$

\begin{tabular}{|c|c|c|c|c|c|c|}
\hline \multirow{2}{*}{\multicolumn{2}{|c|}{ Sample }} & \multirow{2}{*}{$\begin{array}{l}\text { Number of } \\
\text { samples tested }\end{array}$} & \multicolumn{2}{|l|}{$G^{\prime}(\mathrm{Pa})$} & \multicolumn{2}{|l|}{$G^{\prime \prime}(\mathrm{Pa})$} \\
\hline & & & Average & $\begin{array}{l}\text { Standard } \\
\text { deviation }\end{array}$ & Average & $\begin{array}{l}\text { Standard } \\
\text { deviation }\end{array}$ \\
\hline \multicolumn{2}{|c|}{ Liquid phase } & 13 & 0.23 & 0.19 & 0.09 & 0.06 \\
\hline \multirow[t]{2}{*}{ Gel phase } & Immediately after dissection & 14 & 1.86 & 1.14 & 0.61 & 0.39 \\
\hline & $4 \pm 1 \mathrm{~h}$ after dissection & 9 & 6.35 & 3.05 & 1.57 & 0.52 \\
\hline
\end{tabular}

Oscillatory measurements along time were also performed to investigate the time dependency of the storage and loss moduli for a low frequency, $\omega=1 \mathrm{rad} / \mathrm{s}$ (see Fig. 7). The measurements were started right after dissection as described previously. For all samples, $G^{\prime}$ increases slightly in the beginning of the experiment while $G^{\prime \prime}$ remains approximately constant. On the other hand, Nickerson et al. $(2005,2008)$ reported that for a strain amplitude of $\gamma=3 \%$ and a frequency of $\omega=10 \mathrm{rad} / \mathrm{s}$, both the elastic and viscous moduli decrease over time. We found a similar behaviour only for high frequencies ( $\omega=10 \mathrm{rad} / \mathrm{s}$, not shown here). However, after some time (around $60 \mathrm{~min}$ ), both moduli started to vary suddenly suggesting that the sample network was destroyed. As such, we cannot guarantee that the decrease in the moduli was not a result of a degradation process.

\section{Creep experiments}

Figure 8 shows the results of creep tests performed with the liquid phase for two different applied shear stresses, $\tau=1.0$ and $2.0 \mathrm{~Pa}$. The compliance, $J$, is defined as the ratio between the deformation and the applied shear stress, $J(t)=\gamma(t) / \tau$. For

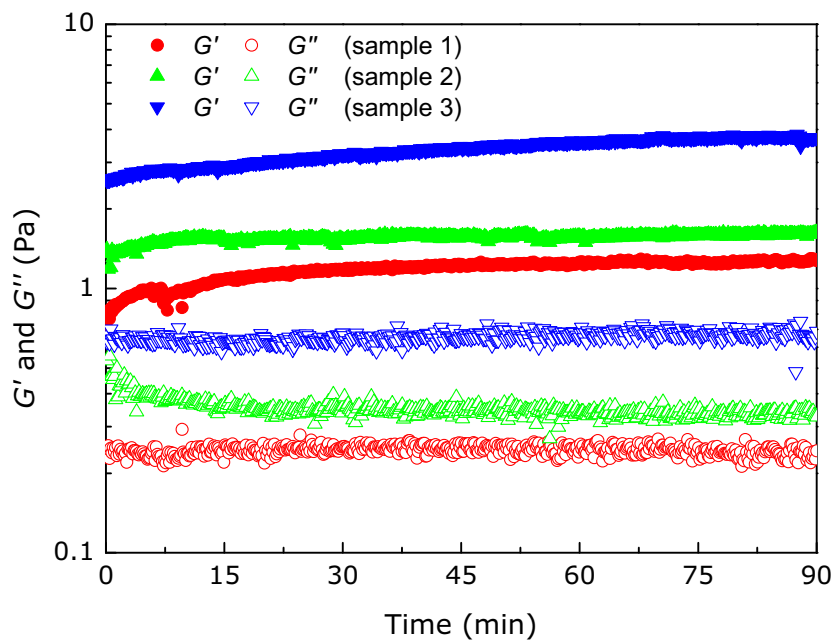

Fig. 7 Elastic $\left(G^{\prime}\right)$ and viscous $\left(G^{\prime \prime}\right)$ moduli variation with time for three independent experiments with the vitreous gel phase right after dissection. The measurements were performed at $T=37^{\circ} \mathrm{C}$ for constant strain, $\gamma=1 \%$, and frequency, $\omega=1 \mathrm{rad} / \mathrm{s}$ small times $(t<30 \mathrm{~s})$, an unsteady behaviour is observed (where instrument inertia can be significant (Ewoldt et al. 2015)), but for larger times, a steady shear flow is approached, with a linear increase of $J$ with time as shown in the inset of Fig. 8. The slope of $J$ as function of time is approximately $10^{3} \mathrm{~Pa}^{-1} \mathrm{~s}^{-1}$, which is approximately the inverse of the shear viscosity at high shear rates shown in Fig. 4.

For the gel phase, the creep test was also performed for two different shear stresses $(\tau=1.0$ and $2.0 \mathrm{~Pa})$ and the results are shown in Fig. 9. Following the methodology presented by Evans et al. (2009) and Tassieri et al. (2016), we converted the measured compliance values to storage and loss moduli. The compliance results measured for shear stresses of 1.0 and $2.0 \mathrm{~Pa}$ when converted to storage and loss moduli are consistent with $G^{\prime}$ and $G^{\prime \prime}$ measured experimentally in SAOS, which are presented in Fig. 6.

Figure 9 shows that the gel phase of $\mathrm{VH}$ behaves as a viscoelastic material and the response for the two different applied shear stresses is qualitatively similar: there is a first region that occurs immediately after the shear stress is applied, and a second delayed region (Mezger 2014). The first region corresponds to the elastic response of the vitreous gel phase to a sudden increase of the shear stress (but instrument inertia can

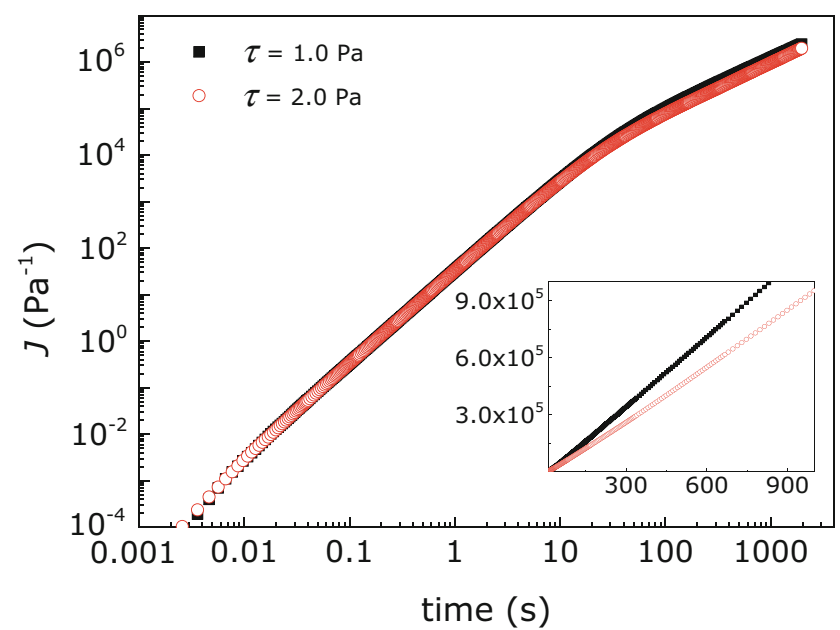

Fig. 8 Compliance of the liquid phase of VH for two different applied shear stresses as a function of time, measured at $T=37^{\circ} \mathrm{C}$ using the coneplate geometry with $60 \mathrm{~mm}$ diameter 
Fig. 9 Compliance of the $\mathrm{VH}$ gel phase at $T=37^{\circ} \mathrm{C}$ plotted as function of time for different applied shear stress values. a $\tau=1.0 \mathrm{~Pa}$. b $\tau=2.0 \mathrm{~Pa}$

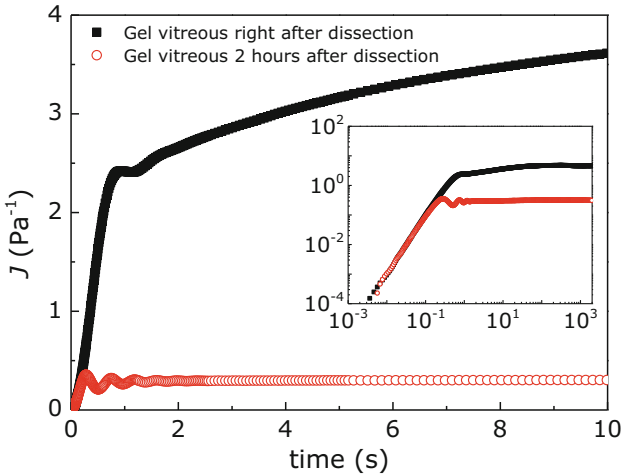

(a)

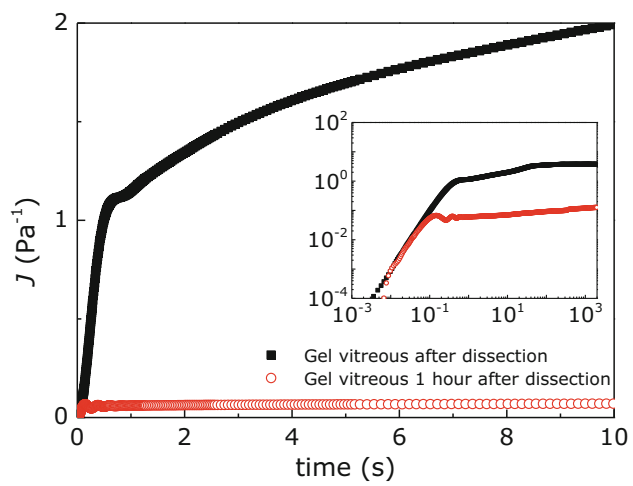

(b) also be important in this region) and occurs for a short time: $t \leq 0.2 \mathrm{~s}$ for the delayed experiments, and $t \leq 1 \mathrm{~s}$ for experiments performed immediately after dissection. The initial region is quickly followed by a delayed elastic region until steady state is reached. Our results show that the compliance is higher right after dissection (maximum values are $J=4.85 \mathrm{~Pa}^{-1}$ for $\tau=1.0 \mathrm{~Pa}$, and $J=3.77 \mathrm{~Pa}^{-1}$ for $\tau=2.0 \mathrm{~Pa}$ ) than a few hours after dissection $\left(J=0.35 \mathrm{~Pa}^{-1}\right.$ for $\tau=1.0 \mathrm{~Pa}$ and $J=0.12 \mathrm{~Pa}^{-1}$ for $\tau=2.0 \mathrm{~Pa}$ ). Based on our SAOS experiments, this behaviour was expected since the compliance plateau is characteristic of the inverse of the elasticity or stiffness of the VH (Evans et al. 2009).

Sharif-Kashani et al. (2011) performed similar measurements for three different applied shear stresses $(\tau=0.5,1.0$, and 2.0 Pa) using porcine eyes, and their results show that lower shear stresses produce higher compliance values. Their maximum compliance values are around $J=2$ and $1 \mathrm{~Pa}^{-1}$ for shear stresses of $\tau=1.0$ and $2.0 \mathrm{~Pa}$, respectively. Kavehpour et al. (2013) measured the compliance values of four distinct pairs of porcine eyes. Although the results are very similar for the same pair of eyes, different values of compliance for different pairs varied in a range between approximately $J=0.02$ and $1 \mathrm{~Pa}^{-1}$.

The compliance values for collagen gel solutions with concentrations of $1 \% \mathrm{w} / \mathrm{w}$ are in the range between $J=1.5$ and $2.8 \mathrm{~Pa}^{-1}$ (Sheu et al. 2001). Similarly to what happens with $G^{\prime}$ and $G^{\prime \prime}$, the compliance values for collagen are comparable to the values obtained for the vitreous gel phases. The results corroborate the idea that, the gel properties are mainly established by the collagen fibrils. Additionally, the study performed by Sakuma et al. (2004), where the authors digested vitreous humour with collagenase (destroying collagen fibrils) and consequently obtained a reduction in vitreous gel elasticity (which in that case was associated with a short time scale in creep experiments), supports the idea that the elastic properties of $\mathrm{VH}$ are mainly caused by the collagen fibrils.

\section{Extensional flow experiments}

Two examples of the time evolution of the liquid filament diameter measured with the CaBER are shown in Fig. 10. The extensional relaxation times were obtained based on the model for a viscoelastic fluid in the elasto-capillary thinning regime, where the filament diameter decays exponentially with time (Entov and Hinch 1997), $D(t) \propto \mathrm{e}^{(-t / 3 \lambda)}$, where $\lambda$ is the fluid relaxation time. Our results show a good agreement between samples from different rabbit eyes. Two exemplifying cases obtained for different strains are shown in Fig. 10 and exhibit approximately the same gradient in a semi-log plot in the exponentially thinning region. The average relaxation time obtained is $\lambda=9.7 \pm 2.2 \mathrm{~ms}$ (based on 12 samples).

A set of extensional flow measurements was performed for specific times between 5 and $150 \mathrm{~min}$ after the dissection of

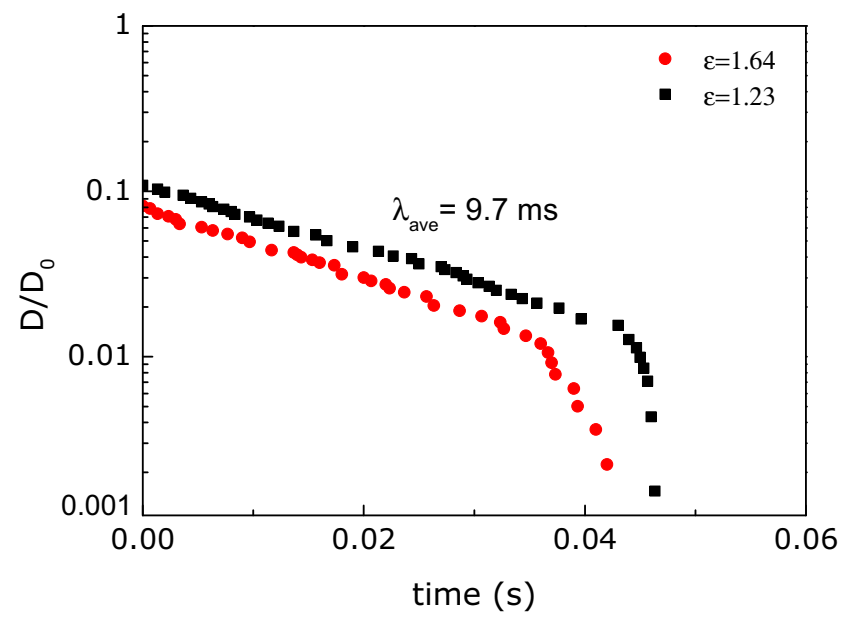

Fig. 10 Time evolution of filament diameter of VH liquid phase, measured with the CaBER at $T=37{ }^{\circ} \mathrm{C}$. The imposed Hencky strains are $\varepsilon=1.23$ and 1.64 , and the samples were submitted to a strike time of $50 \mathrm{~ms}$ for plate separation. The relaxation time obtained from the exponentially thinning region is similar for both samples 
the eye, and the relaxation time was shown to be nearly independent of the time (not shown here).

Bingol et al. (2010) studied the extensional behaviour of sodium hyaluronate and synovial fluid samples. The authors found that the biofluid relaxation time depends strongly of the hyaluronan molecular weight and the concentration of HA. Haward et al. (2013) used an optimised shape cross-slot extensional rheometer (OSCER), to study the elongational flow behaviour and the rheological properties of HA solutions representative of the synovial fluid in the knee joint. The authors tested three different solutions: HA solutions of 0.1 and $0.3 \mathrm{wt} . \%$ in a physiological phosphate-buffered saline (PBS) and a model synovial fluid formed from a solution of $0.3 \mathrm{wt} . \%$ HA combined with $1.1 \mathrm{wt} . \% \mathrm{BSA}$, and $0.7 \mathrm{wt} . \% \gamma$-globulin. The relaxation times of the three solutions are $6.8,16.8$, and $17.2 \mathrm{~ms}$, respectively, which are similar to the relaxation times measured in our samples.

\section{Conclusions}

The shear and extensional rheological properties of vitreous humour were characterised in the liquid and gel phases, both immediately after dissection and several hours after dissection. Both phases show viscoelastic behaviour but significant differences between them were found: the liquid phase exhibits the lowest elastic and viscous moduli, while the gel phase $4 \pm 1 \mathrm{~h}$ after dissection shows the highest values. Creep experiments show that the VH gel phase behaves like a typical viscoelastic gel, presenting an elastic region, followed by a delayed elastic region until steady state is reached. When submitted to steady shear, the liquid phase exhibits a strong shear thinning behaviour achieving a viscosity plateau of $\sim 10^{-3} \mathrm{~Pa}$ s. Experiments with the liquid phase under extensional flow yielded an average relaxation time of $\lambda_{\text {ave }}=9.7 \mathrm{~ms}$, which was found not to change significantly with time after dissection. The surface tension of the liquid phase was also found to be nearly constant within the time frame of the experiments.

The properties of $\mathrm{VH}$ liquid phase and $\mathrm{VH}$ gel phase are consistent with literature data obtained for solutions of HA and collagen, respectively, suggesting that the rheological properties are dictated mainly by the collagen content in the case of the gel phase and by the HA content in the liquid phase.

The detailed rheological characterisation data provided here for the different phases of VH are key to understand the differences in $\mathrm{VH}$ properties due to the liquefaction process that occurs along the different stages of the eye's life, as well as the changes caused in the biofluid structure as a consequence of some diseases. The rheological insight is also crucial for the improvement and development of new drug delivery systems as well as for the development of a new class of vitreous humour substitutes to be used in eye surgery that can mimic its mechanical functionality.

Acknowledgements A.F. Silva gratefully acknowledges the financial support from the Fundação para a Ciência e a Tecnologia through scholarship SFRH/BD/91147/2012. The authors are grateful to Dr Hui-Rong Jiang (Strathclyde Institute of Pharmacy and Biomedical Sciences, University of Strathclyde) for advice on the dissection techniques, to Michael Dunne and Aileen Rankin (Institute of Cardiovascular and Exercise Medicine, University of Glasgow) for providing the rabbit eyes, and to Dr Nicholas Hudson (University of Strathclyde) for helpful discussions. The Compliance to Complex Moduli software provided by $\mathrm{Dr}$ Manlio Tassieri (University of Glasgow) is also gratefully acknowledged.

Open Access This article is distributed under the terms of the Creative Commons Attribution 4.0 International License (http:// creativecommons.org/licenses/by/4.0/), which permits unrestricted use, distribution, and reproduction in any medium, provided you give appropriate credit to the original author(s) and the source, provide a link to the Creative Commons license, and indicate if changes were made.

\section{References}

Ambrosio L, Borzacchiello A, Netti PA, Nicolais L (1999) Rheological study on hyaluronic acid and its derivative solutions. J Macromol Sci A 36:991-1000

Baino F (2010) Scleral buckling biomaterials and implants for retinal detachment surgery. Med Eng Phys 32:945-956

Baino F (2011) Towards an ideal biomaterial for vitreous replacement: historical overview and future trends. Acta Biomater 7:921-935

Balazs EA, Denlinger JL (1982) Ageing changes in the vitreous. In: Dismukes K, Sekular R (eds) Ageing and human visual function, Alan R Liss, Inc, New York, pp 45-57

Barnes HA (2000) A handbook of elementary rheology. University of Wales, Institute of Non-Newtonian Fluid Mechanics, Aberystwyth

Bettelheim FA, Wang TJY (1976) Dynamic viscoelastic properties of bovine vitreous. Exp Eye Res 23:435-441

Bingol AO, Lohmann D, Puschel K, Kulicke WM (2010) Characterization and comparison of shear and extensional flow of sodium hyaluronate and human synovial fluid. Biorheology 47: 205-224

Bishop P (1996) The biochemical structure of mammalian vitreous. Eye 10:664-670

Bishop PN (2000) Structural macromolecules and supramolecular organisation of the vitreous gel. Prog Retin Eye Res 19:323-344

Black J, Hastings GW (1998) Handbook of biomaterial properties. Chapman \& Hall

Bos KJ, Holmes DF, Meadows RS, Kadler KE, McLeod D, Bishop PN (2001) Collagen fibril organisation in mammalian vitreous by freeze etch/rotary shadowing electron microscopy. Micron (Oxford, England: 1993) 32:301-306

Chirila TV, Hong Y, Dalton PD, Constable IJ, Refojo MF (1998) The use of hydrophilic polymers as artificial vitreous. Prog Polym Sci 23: 475-508

de Smet MD, Gad Elkareem AM, Zwinderman AH (2013) The vitreous, the retinal interface in ocular health and disease. Ophthalmologica 230:165-178

del Amo EM, Urtti A (2015) Rabbit as an animal model for intravitreal pharmacokinetics: clinical predictability and quality of the published data. Exp Eye Res 137:111-124

Entov VM, Hinch EJ (1997) Effect of a spectrum of relaxation times on the capillary thinning of a filament of elastic liquid. J NonNewtonian Fluid Mech 72:31-53 
Evans RML, Tassieri M, Auhl D, Waigh TA (2009) Direct conversion of rheological compliance measurements into storage and loss moduli. Phys Rev E 80:012501

Ewoldt RH, Johnston MT, Caretta LM (2015) Experimental challenges of shear rheology: how to avoid bad data. In: Spagnolie SE (ed) Complex fluids in biological systems: experiment, theory, and computation. Springer New York, New York, pp 207-241

Fam H, Kontopoulou M, Bryant JT (2009) Effect of concentration and molecular weight on the rheology of hyaluronic acid/bovine calf serum solutions. Biorheology 46:31-43

Filas BA, Zhang Q, Okamoto RJ, Shui YB, Beebe DC (2014) Enzymatic degradation identifies components responsible for the structural properties of the vitreous body. Invest Ophthalmol Vis Sci 55:55-63

Fromm AW (1921) The vitreous body, its origin, development, and structure as observed in the eye of the pig, by Aloisius William Fromm, Washington, D.C

Haward SJ (2014) Synovial fluid response to extensional flow: effects of dilution and intermolecular interactions. PLoS ONE 9:e92867

Haward SJ, Jaishankar A, Oliveira MSN, Alves MA, McKinley GH (2013) Extensional flow of hyaluronic acid solutions in an optimized microfluidic cross-slot devicea). Biomicrofluidics 7:044108

Kavehpour P, Freeman R, Vedadghavami R, Shah S, Amini R, Hubschman J-P (2013) Mechanical properties of vitreous humor in eye pairs. Invest Ophthalmol Vis Sci 54:3321

Kleinberg TT, Tzekov RT, Stein L, Ravi N, Kaushal S (2011) Vitreous substitutes: a comprehensive review. Surv Ophthalmol 56:300-323

Laude A, Tan LE, Wilson CG, Lascaratos G, Elashry M, Aslam T, Patton N, Dhillon B. (2010) Intravitreal therapy for neovascular age-related macular degeneration and inter-individual variations in vitreous pharmacokinetics. Prog Retin Eye Res 29:466-75

Le Goff MM, Bishop PN (2008) Adult vitreous structure and postnatal changes. Eye 22:1214-1222

Lee B (1992) Comparative rheological studies of the vitreous body of the eye. Dissertations available from ProQuest Paper AAI9227704. http://repositoryupennedu/dissertations/AAI9227704.

Li J, He A, Han CC, Fang D, Hsiao BS, Chu B (2006) Electrospinning of hyaluronic acid (HA) and HA/gelatin blends. Macromol Rapid Commun 27:114-120

Los LI, van der Worp RJ, van Luyn MJA, Hooymans JMM (2003) Agerelated liquefaction of the human vitreous body: LM and TEM evaluation of the role of proteoglycans and collagen. Invest Ophthalmol Vis Sci 44:2828-2833

Lundquist O, Osterlin S (1994) Glucose concentration in the vitreous of nondiabetic and diabetic human eyes. Graefes Arch Clin Exp Ophthalmol 232:71-74

Maleki A, Kjøniksen A-L, Nyström B (2007) Anomalous viscosity behavior in aqueous solutions of hyaluronic acid. Polym Bull 59:217226

Manero O, Bautista F, Soltero JFA, Puig JE (2002) Dynamics of wormlike micelles: the Cox-Merz rule. J Non-Newtonian Fluid Mech 106:1-15

Mezger TG (2014) The rheology handbook: for users of rotational and oscillatory rheometers. Vincentz Network
Mitry D, Fleck BW, Wright AF, Campbell H, Charteris DG (2010) Pathogenesis of rhegmatogenous retinal detachment: predisposing anatomy and cell biology. Retina (Philadelphia, Pa) 30:1561-1572

Nickerson CS, Karageozian HL, Park J, Kornfield JA (2005) Internal tension: a novel hypothesis concerning the mechanical properties of the vitreous humor. Macromol Symp 227:183-190

Nickerson CS, Park J, Kornfield JA, Karageozian H (2008) Rheological properties of the vitreous and the role of hyaluronic acid. J Biomech 41:1840-1846

Picout DR, Ross-Murphy SB (2003) Rheology of biopolymer solutions and gels. TheScientificWorldJOURNAL 3:105-121

Ross A, Blake RC 2nd, Ayyala RS (2010) Surface tension of aqueous humor. J Glaucoma 19:456-459

Sakuma T, Won Y-Y, Sueda J, Usumoto N, Weitz DA, Hirose T (2004) Rheology of vitreous : effects of enzymes. Invest Ophthalmol Vis Sci 45:1948

Sebag J (1987) Ageing of the vitreous. Eye 1:254-262

Sebag J (1993) Abnormalities of human vitreous structure in diabetes. Graefes Arch Clin Exp Ophthalmol 231:257-260

Sebag J (2002) Imaging vitreous. Eye 16:429-439

Sebag J, Balazs EA (1985) Human vitreous fibres and vitreoretinal disease. Trans Ophthalmol Soc U K 104:123-128

Sebag J, Nie S, Reiser K, Charles MA, Yu NT (1994) Raman spectroscopy of human vitreous in proliferative diabetic retinopathy. Invest Ophthalmol Vis Sci 35:2976-2980

Sharif-Kashani P, Hubschman JP, Sassoon D, Kavehpour HP (2011) Rheology of the vitreous gel: effects of macromolecule organization on the viscoelastic properties. J Biomech 44:419-423

Shayegan M, Forde NR (2013) Microrheological characterization of collagen systems: from molecular solutions to fibrillar gels. PLoS ONE 8:e70590

Sheu MT, Huang JC, Yeh GC, Ho HO (2001) Characterization of collagen gel solutions and collagen matrices for cell culture. Biomaterials 22:1713-1719

Siggers JH, Ethier CR (2012) Fluid mechanics of the eye. Annu Rev Fluid Mech 44:347-372

Stitt AW (2005) The Maillard reaction in eye diseases. Ann N Y Acad Sci 1043:582-597

Stitt AW, Moore JE, Sharkey JA, Murphy G, Simpson DA, Bucala R, Vlassara H, Archer DB (1998) Advanced glycation end products in vitreous: structural and functional implications for diabetic vitreopathy. Invest Ophthalmol Vis Sci 39:2517-2523

Swindle KE, Hamilton PD, Ravi N (2008) In situ formation of hydrogels as vitreous substitutes: viscoelastic comparison to porcine vitreous. J Biomed Mater Res A 87A:656-665

Swindle KE, Ravi N (2007) Recent advances in polymeric vitreous substitutes. Expert Rev Ophthalmol 2:255-265

Tassieri M, Laurati M, Curtis DJ, Auhl DW, Coppola S, Scalfati A, Hawkins K, Williams PR, Cooper JM (2016) i-Rheo: measuring the materials' linear viscoelastic properties "in a step"! J Rheol 60: 649-660

Walton KA, Meyer CH, Harkrider CJ, Cox TA, Toth CA (2002) Agerelated changes in vitreous mobility as measured by video B scan ultrasound. Exp Eye Res 74:173-180 